\title{
Queer as a Zombie: metaforizações da homofobia na ficção televisiva
}

\section{Queer as a Zombie: metaphorizations of homophobia in television fiction}

\author{
Anderson Lopes da Silva ${ }^{1}$
} Linguagens e Discursos nos Meios de Comunicação), vinculado à USP/CNPq, e do NEFICS (Núcleo de Estudos em Ficção Seriada e Audiovisualidades), vinculado à UFPR/CNPq. Tem interesses de pesquisas no campo dos estudos televisivos e do audiovisual, estudos da linguagem, estudos culturais, teorias do excesso e, finalmente, estudos sobre produção, circulação e consumo de ficção seriada em plataformas de streaming. E-mail: anderlopps@gmail.com. 


\section{Resumo}

Mais do que simplesmente apresentar uma tenebrosa e angustiante imagem, a figura dos mortos-vivos traz a possibilidade de múltiplas leituras metafóricas acerca do que esses seres podem falar sobre nossa sociedade e os seus mais diversos dilemas. Assim, a proposta deste artigo é discutir como a série britânica In the flesh metaforiza a homofobia a partir das questões de gênero e sexualidade nas relações afetivas de personagens zumbis e gays da trama. A metodologia baseiase no estudo da metaforização discursiva e, de maneira intrínseca a ela, utiliza-se do conceito de isotopia discursiva como o direcionador preponderante de análise. Finalmente, as considerações finais apontam que a trama da obra desvela exemplos de metaforização discursiva a partir da homofobia familiar, homofobia clínica, homofobia religiosa, homofobia institucionalmente persecutória e homofobia interiorizada.

\section{Palavras-chave}

Zombie Studies, séries, metáfora, sentimentalização, zumbis.

\section{Abstract}

More than simply presenting an eery and lurid image, the figure of the undead brings the possibility of multiple metaphorical readings about what these beings can talk about our society and our most diverse dilemmas. Thus, the main purpose of this article is to discuss how the British series In the flesh metaphorizes homophobia based on gender and sexuality issues through the affective relationships of zombie and gay characters in the plot. The methodology is based on the study of discursive metaphorization and, in an intrinsic way, it uses the concept of discursive isotopy as the predominant operator of analysis. Finally, the conclusions point out that this TV series reveals examples of discursive metaphorizations based on family homophobia, clinical homophobia, religious homophobia, institutionally persecutory homophobia, and internalized homophobia.

\section{Keywords}

Zombie Studies, TV series, metaphor, sentimentalization, zombies. 
"Por que um texto acadêmico se dedica ao estudo dos zumbis?". Essa pergunta - seja pela sinceridade da dúvida, seja pela provocação que antecipa o demérito de um juízo de valor - é algo que ronda a constituição deste artigo desde o início de uma pesquisa que tomava os mortos-vivos como tema de estudo, em 2016. Tal questionamento é justificado tanto pela dificuldade de determinados públicos acadêmicos compreenderem o que se poderia ter de "útil" ou "necessário" em uma investigação que observa os zumbis pela via dos estudos televisivos e comunicacionais, quanto pela ausência de uma linha investigativa pré-estabelecida e popularmente conhecida nos bancos universitários que fizesse dos zumbis o seu foco de trabalho (e, vale notar, as duas situações são retroalimentávies posto que torna-se pouco possível achar interessante ou necessária a existência de uma pesquisa sobre zumbi se não há uma tradição científica ou mesmo abertura que transforme esse interesse em debate acadêmico e vice-versa).

Por essa ótica, a resposta mais curta e direta à pergunta que abre este artigo poderia ser traduzida da seguinte forma: "Porque eles, os zumbis, são relevantes ao entedimento de como funcionam, se estruturam, reagem e se movimentam as sociedades frente à diferença". Todavia, como tentativa de uma resposta mais aprofundada, este artigo propõe o estudo dos zumbis com os objetivos de identificar, discutir e analisar os processos de metaforização da homossexualidade colocados na trama da série britânica In the flesh (BBC3, 2013-2015). Aqui, os zumbis² são vistos como materialidades empíricas relevantes às reflexões sobre a concepções de abjeção e de desejo, além da observação das relações entre alteridade e diferença. Ao retratar um mundo pós-apocalíptico no qual existe a necessidade de convivência mútua entre humanos e zumbis, a obra oportuniza a este artigo o descortinar das produções de sentido envolvidas nas metaforizações discursivas acerca de personagens abjetas-desejadas como um fenômeno que extrapola o espaço ficcional para tocar e afetar as esferas da vida real e concreta.

2 Neste artigo usam-se os termos "morto-vivo", "desmorto" e "zumbi" como sinônimos. Todavia, não se deve confundir a ideia de morto-vivo aqui discutida como ampla o suficiente para também abarcar outras manifestações fantásticas e espectrais como os fantasmas ou vampiros. 
Para tanto, a estrutura deste trabalho é dividida em quatro partes: 1) A relação entre os estudos das figuras zumbificadas (Zombie Studies) com as discussões sobre a diferença e a homofobia; 2) O processo de sentimentalização presente em obras televisivas que retratam o zumbi como forma mobilizadora das concepções de abjeção e afeto; 3) A apresentação da metaforização discursiva e, especificamente, do conceito de isotopia discursiva como formas de aproximação e abordagem empírica da obra em estudo; e, finalmente, 4) A análise das metaforizações da homofobia registradas no relato ficcional de In the flesh.

\section{Os Zombie Studies, a diferença e a homofobia}

O interesse pela figura do zumbi tem seu nascedouro no campo míticocultural disposto pelas práticas religiosas do vodu, especialmente a partir da ressignificação dada pelos povos caribenhos à versão originária dos cultos trazidos pelos povos africanos no processo de escravização. Tendo o Haiti como o palco central dessa discussão, Handerson (2010) afirma que a crença zumbi está extremamente conectada aos processos de luta e resistência dos escravizados afro-caribenhos frente ao escravizador-colonial. Na esteira desse raciocínio, Dendle (2001) acrescenta que o termo "zumbi", de origem quimbunda, significa a ideia do morto que se levanta de sua sepultura por meio de histórias que giravam ao redor de trabalhadores controlados por um poderoso feiticeiro (geralmente denominado como "bokor") que os retirava, já depois de mortos, de suas covas e os faziam trabalhar eternamente nas lavouras. O enredo popular tinha íntima ligação com o medo colocado por parte dos senhores de escravos que, temendo o alto nível de suicídio de sua mão de obra escrava, tentavam assustá-los com essa terrível maldição vinda no pós-morte (HURSTON, 1938).

Ainda sobre o assunto, Handerson explica que é o "bokor" o responsável pelo processo de letargia presente na figura do zumbi: "[...] ele fica num estado de idiotice, obedece a tudo que o mandam fazer. [...]. Geralmente no meio rural, o dono do zombi explora-o, forçando-o a trabalhar no seu rebanho" (HANDERSON, 2010, p. 138). Representações audiovisuais próximas desse 
estado de letargia e controle do zumbi por um ser vil são a chave de leitura do primeiro longa-metragem a abordar o tema: em White Zombie (1932), dirigido por Victor Hugo Halperin, a representação da subida dos mortos ao mundo dos vivos dá-se pela personagem Madeleine (Madge Bellamy), a noiva-cadáver que é controlada por "Murder" Legendre (Bela Lugosi), o feiticeiro.

Com o passar das décadas, segundo Reis Filho e Suppia (2011), as transformações na representação afastam-se da zumbificação à moda haitiana para alcançar um processo de laicização. O contexto das produções estadunidenses é o centro disso, pois é nele que a figura do zumbi ganha uma projeção nunca vista, como mostra o filme A noite dos mortos-vivos (1968), dirigido por George A. Romero. Assim, não mais apenas um zumbi, mas, agora, uma abjeta horda faminta por carne humana é quem toma conta das telas. "Para ele [Romero], o importante são os conflitos desencadeados entre aqueles que se deparam com a situação posta. Por isso, os mortos dos filmes de Romero são desconfortavelmente comuns e familiares" (SUPPIA; REIS FILHO, 2013, p. 37).

Nesse sentido, os Estudos de Zumbis (Zombie Studies) assentam-se na perspectiva transdisciplinar mais como uma possibilidade de compreensão e reflexão sobre o "mundo dos vivos" e seu entorno social por entre questões socioculturais e político-econômicas do que apenas uma investigação dos modos narrativos ou da constituição desses personagens no universo ficcional da literatura, do cinema, da TV, dos jogos e afins. Para se ter uma ideia da abrangência do campo, já existem iniciativas de cursos e disciplinas com a temática do Zombie Studies colocadas de modo gradual e sistemático nos espaços universitários dos Estados Unidos, como afirma Kyle Bishop (2015). Segundo o autor: "Hoje [...], os Zombie Studies podem ser prontamente encontrados nos currículos acadêmicos, nas publicações acadêmicas e por toda a internet tanto nos círculos acadêmicos, quanto nos jornalísticos" (BISHOP, 2015, p. 1). Por outro lado, mesmo que epistemologicamente transdisciplinar, o campo dos Zombie Studies ainda não goza de um status que o considera reconhecido ou significativo dentro das Humanidades e das Ciências Sociais no Brasil e na América Latina. 
Já acerca da diferença, como ponto relevante da discussão aqui empreendida, inicia-se o entendimento do termo enquanto categoria comum a todas as discussões intersecionais ${ }^{3}$ que perpassam a figura do zumbi frente aos debates de classe social, de raça, de gênero e de deficiência. Por isso, é em Guacira Lopes Louro (1997) que se estabelece a linha organizadora das discussões acerca do outro enquanto "o diferente" ou aquele que é atravessado pela "diferença". Assim: "Aqui nos interessa salientar, acima de tudo, o fato de que a atribuição da diferença está sempre implicada em relações de poder, a diferença é nomeada a partir de um determinado lugar que se coloca como referência" (LOURO, 1997, p. 47).

Nessa perspectiva trazida pela autora, a discussão sobre como o campo dos Zombie Studies modela e coloca as questões interseccionais em discussão, compartilha da ideia de que: "A atribuição da diferença é sempre historicamente contingente - ela é dependente de uma situação e de um momento particulares" (LOURO, 1997, p. 50). Ou seja: a diferença é sempre temporal e espacialmente localizada em experiências particulares, mas também coletivas; sempre se dá a ver por vieses que recaem sobre a vida cotidiana de indivíduos, mas também está sob a tutela de estruturas e sistemas nem sempre visíveis aos olhos de todos. Logo, o diferente e a diferença tratados na leitura que aqui se faz dos Zombie Studies em relação a assuntos interseccionais tão relevantes não perdem de vista, tacitamente, as perguntas sobre quem é o definidor da diferença e quem é considerado o diferente. $\mathrm{E}$, assim, ao fim, conecta-se esse debate à ideia de que o que está em jogo realmente, como pontua Louro (1997, p. 45-46), são as desigualdades de classe, raça, gênero e deficiência, exemplificadas na dimensão da ficcionalidade e vivenciadas na dimensão da realidade.

Por sua vez, no caso específico da homofobia, como relembra Borrillo (2010), o termo condensa muitos significados sob uma mesma palavra. Todavia, é possível entender a homofobia como "uma manifestação arbitrária que consiste que: "A interseccionalidade visa dar instrumentalidade teórico-metodológica à inseparabilidade estrutural do racismo, capitalismo e cisheteropatriarcado [...]". A essa definição, acrescenta-se a inseparabilidade de todos esses assuntos ao campo dos estudos de deficiência e capacitismo. 
em designar o outro como contrário, inferior ou anormal; por sua diferença irredutível, ele é posicionado a distância, fora do universo comum dos humanos" (BORRILLO, 2010, p. 13). Esse entendimento da homofobia é, em grande medida, alicerçado sob uma visão religiosa que insiste em não apenas direcionar a vida dos seus afiliados na fé, como também, coloca sua cosmovisão enquanto estrutura de pensamento para além da membresia:

\begin{abstract}
A relativa tolerância que o mundo pagão havia reservado às relações homossexuais contrasta, consideravelmente, com a hostilidade do cristianismo triunfante. A condenação da sodomia na tradição judaico-cristã - pedra angular do sistema repressivo - aparece como o elemento precursor fundamental das diferentes formas de homofobia (BORRILLO, 2010, p. 18).
\end{abstract}

Traçando as raízes da homofobia da Grécia Antiga e do Império Romano até a Era Moderna, Allen (2006, p. 148) também destaca o Cristianismo como o verdadeiro "triunfo" da homofobia 4 . Para o autor, a homofobia moderna reside centralmente na possibilidade de desumanização (em um processo de monsterfication) sistematicamente atrelado a uma quase eterna perseguição explícita ou implícita às pessoas gays, seja por meio da patologização clínica ou mesmo por uma judicialização que insiste em criminalizar determinadas existências dissidentes (ALLEN, 2006, p. 185-186). É importante saber que a homofobia ganha contornos singulares não apenas em termos históricos, mas, principalmente, em contextualização estrutural. Em outras palavras, como sinaliza Borrillo (2010, p. 24-30), é possível pensar em estágios reflexivos do assunto a partir da:

1. Homofobia irracional (a aversão fóbica em forma de resposta puramente emotiva, o medo, a repulsa e o asco às pessoas homossexuais) e homofobia cognitiva (socialmente como um processo que intenta perpetuar a diferença homo/hétero pela intolerância, violência estigmatizadora, construção de leis homofóbicas etc.),

É importante assinalar que essa é uma visão que não deve ser generalizada. Há, mesmo dentro do seio das igrejas católicas (romanas e ortodoxas) e protestantes (nas suas mais variadas denominações), alguns poucos espaços que ainda perseveram por ter um olhar mais progressista e inclusivo sobre as questões da homossexualidade, direitos humanos e religião. 
2. Homofobia geral (como o termo diz, pressupõe o entendimento de pessoas homossexuais como "traidoras" que se desviam do "gênero correto", que discriminam homens que não "querem" ser homens ou mulheres que não "querem" ser mulheres, um entendimento confuso sobre gênero e orientação sexual, em grande parte das vezes) e, por fim, homofobia específica (com um ódio dirigido singularmente às peculiaridades das práticas sexuais de homens ou mulheres homossexuais (lesbofobia), tendo, no caso dos homens, uma discussão que ainda intenta separar o aceitável do inaceitável, em termos de "ser passivo" ou "ser ativo" no ato sexual entre homens).

Além disso, em termos de situacionalidades, vê-se que a homofobia pode se desdobrar em outras categorias associativas com o sexismo, o heterossexismo, o racismo, a xenofobia, o classismo e, ainda que não mencionado diretamente pelo autor, o capacitismo (BORRILLO, 2010). Na atualidade, ainda há autores que conectam as discussões conceituais sobre o assunto a partir de uma reflexão que vê o uso do termo homofobia como válido e potente em contextos políticos, mas que, em uma ampliação da compreensão de tal fenômeno, veem a expressão "preconceito contra diversidade sexual" como uma alternativa sinonímica ou ainda mais operacionalizável de ser aplicada empiricamente (COSTA; NARDI, 2015, p. 724).

\section{A sentimentalização do zumbi como força mobilizadora da abjeção e do desejo}

No caso específico desse artigo, o foco volta-se para compreender um tipo muito sui generis de representação do zumbi que não se atrela à representação voduísta e, diretamente, também não se encaixa nas representações romereanas. Trata-se do zumbi sentimentalizado (GARCÍA MARTÍNEZ, 2016), ou seja, mortosvivos peculiares que têm uma caracterização (física e psicológica) direcionada a enfatizar a humanização, a racionalidade e a sentimentalização das personagens. Em outras palavras, são mortos-vivos que falam e estão dotados de memória, de nostalgia e que, ao voltar de seus túmulos, têm de lidar com a vida novamente 
e, inclusive, com seus problemas familiares e relacionamentos amorosos ${ }^{5}$. Além disso, não necessariamente eles têm a aparência monstruosa de outros zumbis e nem sempre são retratados como figuras que se alimentam de carne humana.

$\mathrm{Na}$ base da sentimentalização está a hipótese de que a virada ou o giro afetivo (affective turn) produz um deslocamento do olhar social (e da pesquisa acadêmica, em específico) para a subjetividade, as emoções, os afetos, as experiências humanas, as relações, os sentimentos e a alteridade como partes preponderantes da formação do sujeito, tal qual destaca Clough (2007). Um dos espaços de produção de sentido mais nítido desse giro afetivo pode ser visto, por exemplo, nos estudos nos quais o corpo é o foco da análise principal como, por exemplo, os estudos feministas e as pesquisas que têm nas teorias queer os seus fundamentos. De acordo com Clough (2007, p. 3): "A virada afetiva convida a uma abordagem transdisciplinar da teoria e do método que necessariamente também convida à experimentação para capturar a mudança de co-funcionamento do político, do econômico e do cultural [...]".

O trabalho de Alejandro García Martínez e Ana Marta González (2016, p. 21) é um exemplo de como esse giro afetivo dialoga muito com a concepção de cultura emocional presente nas séries contemporâneas como reflexo de novas estruturas sociais que passam a gerir as emoções como algo de suma importância. Desse modo, séries como Les revenants (2012, França), In the flesh (2013-2015, Reino Unido), Resurrection (2014, EUA), Zombie (2015, EUA), Glitch (2015, Austrália) e Amorteamo (2015, Brasil) são exemplos de obras dotadas desta cultura emocional e, por isso, conseguem se diferenciar de representações mais tradicionais dos desmortos porque nelas o zumbi tem a capacidade de sentir (SILVA; GARCÍA MARTINEZ, 2017). treinamento que, preservadas nos zumbis, não o deixam completamente monstruosos, como aponta McDaniel (2016, p. 425). Exemplos disso podem ser vistos no personagem romereano Bub (Sherman Howard) do filme Dia dos mortos (1985) ou em obras mais recentes como os personagens Coffee Zombie (Iggy Pop) e Mallory O'Brien (Carol Kane) de Os mortos não morrem (2019), do diretor Jim Jarmusch. Todavia, o salto qualitativo de representação aqui discutido considera que, além da memória e do condicionamento, os processos de sentimentalização necessariamente precisam envolver racionalização, consciência e produção de relatos afetivos e emocionais por parte dos zumbis. 
Nos dizeres de Szanter e Richards (2017), estas formas de relato promovem um processo de romantização da figura do zumbi como alguém válido e digno da empatia e afeto alheios, como um "outro significativo" que também sente, emocionase e vive seus amores mesmo depois da morte. Uma personagem que vai muito além da tradicional representação do morto-vivo como o ser faminto por vísceras e cérebros e sem processo racionalizante algum. Em síntese: "[...] Se o zumbi era puro instinto, faminto por comer vísceras humanas, estas séries localizam esse tipo particular de zumbi em um terreno estético e moral onde eles [...] se humanizam. São empáticos. São redimíveis" (SILVA; GARCÍA MARTINEZ, 2017, p. 291).

Acerca da abjeção no contexto da cultura zumbi, conforme o pioneiro trabalho de McInthosh e Levrette (2008, p. 128) explicita: "O abjeto ameaça a vida e, portanto, precisa ser 'radicalmente excluído' do espaço dos sujeitos viventes". De igual importância, para compreender como a situação insólita da existência do zumbi causa reações que vão do medo à abjeção, ainda vale lembrar o que afirma Kristeva (1985, p. 4) sobre o assunto: "Não é a falta de limpeza ou saúde que causa abjeção, mas o que perturba a identidade, o sistema, a ordem. O que não respeita limites, posições, regras. O 'entre-dois', o ambíguo, o compósito". Logo, não é tanto a aparência putrefata ou grotesca de um morto-vivo que assusta ou causa incômodo na literatura, no cinema ou na série em estudo, mas sim, o que causa a existência rebelde do zumbi como contrária à sequência natural e normal da vida. Assim, vê-se no cadáver a finitude do ser e no morto-vivo tal finitude se transforma em algo não compreensível no universo físico de leis rígidas sobre a vida e a morte. Dessa forma, os mortos-vivos, estando na condição de passagem, parecem quebrar mais facilmente a angústia da finitude. Todavia, eles trazem consigo outra questão ainda mais aflitiva: uma existência deslocada dos padrões de referência prévios até então vivenciados pelos humanos.

É importante destacar que, na perspectiva de Butler (2003), a abjeção é um processo discursivo - posto que os corpos não vivem fora dos discursos. É justamente por esse motivo que as representações sobre os corpos (e suas identidades, sexualidades e possibilidades de existência) na cultura audiovisual 
é tão relevante. Quando a diferença é vista como abjeta isso significa, conforme Butler (2003, p. 39) que "[...] certos tipos de 'identidade' não possam 'existir' isto é, aquelas em que o gênero não decorre do sexo e aquelas em que as práticas do desejo não 'decorrem' nem do 'sexo' nem do 'gênero'".

Porém, quando, para além da abjeção, entram em jogo as relações conflituosas entre os mortos-vivos a partir da esfera sentimental e afetiva, outro elemento necessariamente passa a fazer parte da narrativa: o desejo. Esse desejo aliado à abjeção, de maneira paradoxal, é matéria de discussão para Wright (2018, p. ix) quando o autor traz a seguinte afirmação: "Os monstros [entre eles, o morto-vivo/zumbi] nos mostram coisas que nós queremos secretamente a qualquer custo". Ainda mais específicas ao campo dos Zombie Studies são as discussões trazidas pelas pesquisas de McGlotten e Jones (2014) e Szanter e Richards (2017) ao colocarem em pauta a complexidade das questões de afeto e desejo envolvendo, no campo da ficção, os zumbis. De acordo McGlotten e Jones (2014) a problemática dos desejos envolve a área das sexualidades, dos tabus e dos interditos. E, especificamente, a partir da correlação entre vida e morte, a situação tende a se tornar ainda mais sui generis.

Assim, McGlotten e Jones (2014, p. 2) afirmam que: "[...] a combinação nada palatável entre zumbis e sexo é provocativa, ativando vários gatilhos de uma miríade de questões sobre a natureza do desejo, do sexo, sexualidade e as políticas de nossos comportamentos sexuais". Logo, dada a ubiquidade do sexo na vida de todas as pessoas (e, no caso das séries com mortos-vivos, também após a vida), é preciso entender como, nesse contexto: "Os zumbis cristalizam medos e desejos relacionados ao contágio e ao consumo, ao corpo e à sociabilidade, à autonomia e à subjugação" (McGLOTTEN; JONES, 2014, p. 2).

\section{A metaforização discursiva: procedimentos metodológicos}

A análise das narrativas de zumbis pela via do estudo das representações metafóricas é algo que possui uma trajetória que não se poderia classificar como extremente inovadora no mundo da pesquisa. Pensar os zumbis e aliá-los às 
metáforas sociais, culturais, políticas e econômicas é um lugar analítico acessado mesmo nas leituras efetuadas pelas críticas cinematográfica e televisiva à parte do discurso acadêmico. Como Vervaeke, Mastropietro e Miscevic (2017) afirmam, pensar metaforicamente o zumbi na cultura ocidental é uma forma de entender o zeitgeist que conforma o nosso tecido social e que, por fim, Ihe dá acabamento ético-estético. Algo que reverbera, no caso dos estudos sobre zumbis presentes em série, a relevância também das análises que têm seu escopo firmado no campo da televisão (GARCÍA MARTÍNEZ; GONZÁLEZ, 2016, p. 22).

Nesse sentido, não se usa aqui o termo metáfora como uma palavra de senso comum que descreveria, grosso modo, o que estas obras poderiam ou teriam a falar sobre a humanidade e o seu entorno social nas entrelinhas. Ao contrário, o que se pressupõe como abordagem empírica dos processos de produção de sentido refletidos e refratados na série In the flesh é o estudo da metaforização. Assim, como forma de fugir das mobilizações oportunísticas da metáfora apenas na tentativa de gerar resultados analíticos superficiais e óbvios, opta-se neste artigo pelos estudos de Roberto Lopes Leite (2007; 2008; 2009) acerca da metaforização discursiva como a parte preponderante dos protocolos metodológicos.

Desse modo, em termos mais práticos, o entendimento dos processos de metaforização não são estudados aqui pelas ideias de metáfora-palavra, isto é, a metáfora que se manifesta apenas enquanto uma unidade lexical, e nem metáfora-sentença, ou seja, a metáfora que se localiza em um "enunciado impertinente" e que, assim, torna-se o "o resultado da interação entre teor e veículo [...]", como explica Leite (2009, p. 122-123). Na mesma linha de raciocínio, este trabalho também não se apropria das definições mais tradicionais advindas das teorias substitutistas (nas quais a metáfora é produzida pela substituição e pelo deslocamento de seu sentido literal de uma palavra à outra) ou comparatistas (nas quais a metáfora é produzida pela comparação implícita e análoga entre termos ou sentenças com a finalidade de produzir sentidos outros), conforme as caracteriza Leite (2007, p. 10). Escolhe-se, 
então, como princípio direcionador da análise, o entendimento dos processos de metaforização pela discursividade enquanto a terceira alternativa pensada pelo autor:

Arrimados nessa proposta, compreendemos que o surgimento da metáfora no plano discursivo deixa de ser um simples jogo de figuras e passa a ser um mecanismo de constituição de sentidos. Logo, nessa nova dimensão de análise, esvanecem-se de tal modo os limites da palavra e da sentença, que o sentido metafórico já não pode ser encontrado em um só lugar, senão no contínuo da significação textual (LEITE, 2009, p. 123).

Assim, continua o pesquisador, é pela materialidade do discurso presente no texto que olhar analítico para o entendimento da metaforização deve se voltar: "[...] A esse fenômeno capaz de engendrar ou multiplicar o sentido metafórico durante o ato interpretativo, damos o nome de metaforização textual", afirma Leite (2009, p. 123). Contudo, há que se destacar que a ideia de texto para Leite é relida aqui para espaços de significação mais abrangentes do que propriamente a textualidade escrita: este artigo percebe o texto televisivo, a partir de Mittell (2010, p. 9-10), também como uma empiria possível e complexa na observação da metaforização.

Por isso, o recorte empírico das cenas em análise não corresponde necessariamente à importância daquele acontecimento narrativo ao começo, meio ou fim da trama. Ao contrário, a seleção das cenas ocorre pela evidenciação temática da homofobia presente em determinados momentos do relato narrativo que, na análise, são interpretados pela isotopia discursiva como processos de metaforização. Desse modo, dada a contingência espacial deste texto, são escolhidas

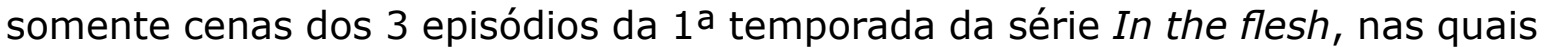
as questões de gênero e sexualidade se fazem presentes direta ou indiretamente nas relações afetivas de personagens zumbis e gays da trama.

Dessa maneira, entre os mecanismos de interpretação utilizados no processo de interpretação da metaforização, este artigo opta por destacar o conceito de isotopia discursiva como o princípio delineador de análise. Tal conceito, 
de inspiração gremaisiana e desenvolvimento betrandiano (LEITE, 2007, p. 131), é utilizado no entendimento do autor a partir de um afastamento da perspectiva estruturalista que o origina para funcionar "[...] como um dispositivo capaz de revelar e reger a coexistência de dois ou mais planos de significação metafóricos no texto durante a interpretação, garantindo, assim, o alçamento da metáfora para o nível discursivo" (LEITE, 2009, p. 121). Logo, na intencionalidade de resumir o percurso epistemológico construído por Leite $(2007 ; 2008 ; 2009)$, a Figura 1 apresenta, então, sobre qual entendimento de metaforização este trabalho se debruça quando propõe a analisar a obra em estudo:

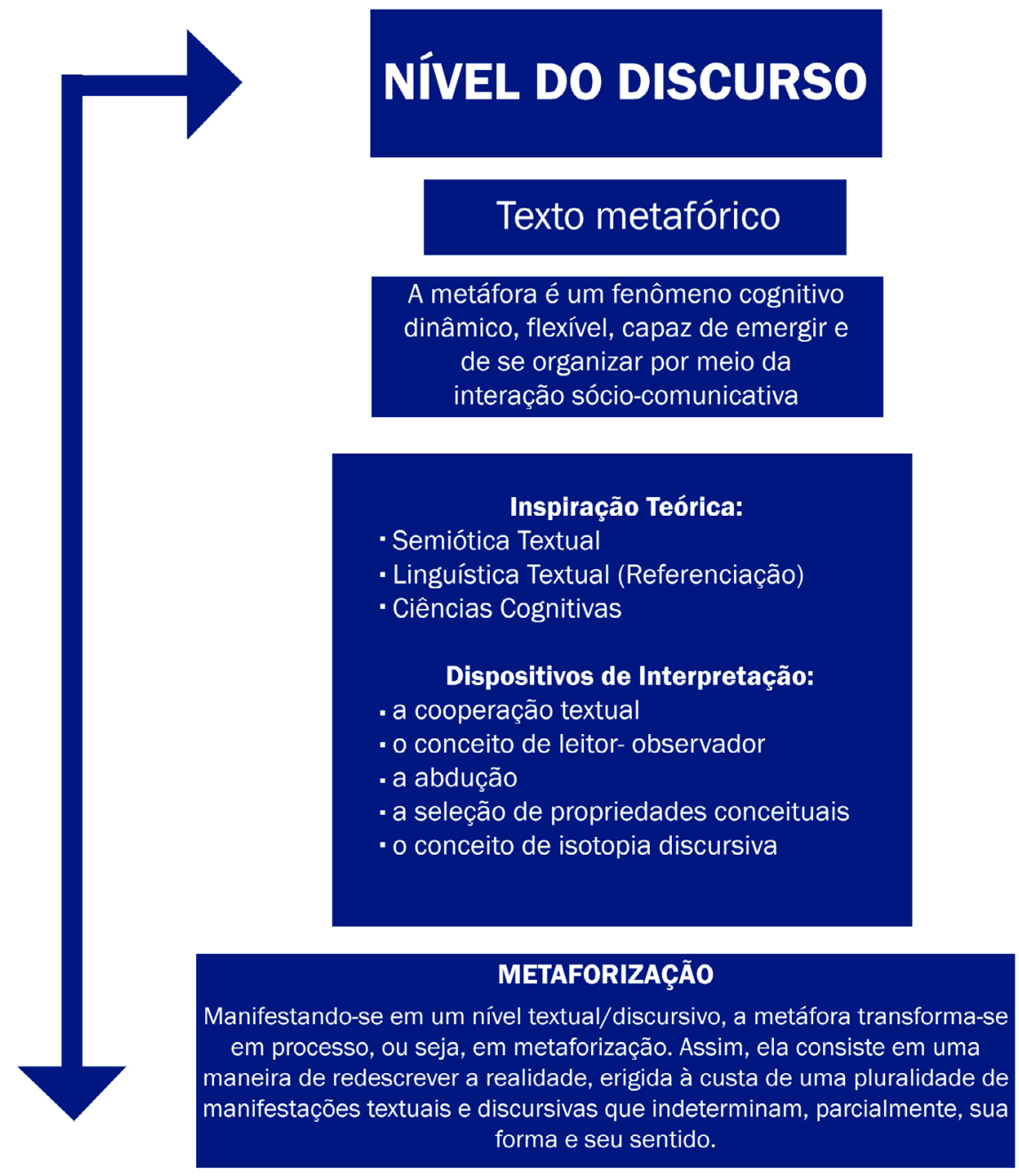

Figura 1. Diagrama teórico-metodológico da metaforização.

Fonte: Elaborado pelo autor (2020) com base na obra de Leite (2007; 2008; 2009). 


\section{Análise das metaforizações da homofobia em In the flesh}

A série In the flesh aborda o cotidiano da pequena Roarton, uma cidade que, além de conviver com a volta misteriosa dos mortos-vivos durante um período chamado "a ascensão" (the rising), agora precisa saber lidar com reintegração de alguns deles à vida social, familiar e profissional. Estudos sobre a obra sinalizam abordagens que caminham lado a lado dos debates sobre gênero, sexualidade e identidades, como demonstram os trabalhos de Coutinho (2016), Montes (2017) e Aiossa (2018). Isso se dá, acima de tudo, pela importância de Kieren como o protagonista gay e zumbi na trama criada por Dominic Mitchell.

Exibida entre 2013 ( $1^{a}$. temporada) e 2015 ( $2^{a}$. temporada) pela BBC3, a trama de In the flesh inicia-se com a volta de Kieren à casa dos pais após um processo de reabilitação proposto pelo governo na tentativa de recuperação dos mortos-vivos (chamados cientificamente de portadores da Síndrome de Morte Parcial (SMP)). Em seu processo de readaptação, Kieren ainda tem que lidar com o preconceito da sociedade e da própria irmã que, depois da volta dos mortos, alistou-se em uma milícia paramilitar contra os desmortos. A situação ganha um contorno ainda mais sui generis quando o jovem Ricky também volta do mundo dos mortos à cidade, reabilitado e em completa negação da sua atual condição. O amor da adolescência, proibido e malvisto pela sociedade, faz com que Kieren e Ricky vivam uma relação que transite no devir, que nunca se concretiza. No período pré-volta dos mortos-vivos, a causa de morte de Kieren (suicídio) se dá pela constante decepção do amor proibido e pela homofobia que o jovem vive, enquanto a morte de Ricky se dá durante a sua participação como soldado no campo de batalha.

Eles tentam novamente um novo romance, no plano dos mortos-vivos, mas como a homofobia aliada ao preconceito dos vivos com os zumbis é muito grande, o relacionamento dos dois não ocorre e o pior acontece: o pai de Ricky brutalmente mata o filho zumbi e Kieren se vê novamente abandonado. Na breve aparição de Ricky, o jovem é mostrado como um morto-vivo que também sofre por erros do passado (especialmente pelo questionamento de não conseguir 
ter coragem para se assumir e para sustentar a relação amorosa com Kieren). Além disso, ele tem dificuldades de compreender sua nova identidade numa sociedade que o valoriza por ser um combatente de guerra, mas simultaneamente o rejeita por sua condição de zumbi (e gay não-assumido).

A homofobia de viés familiar (BORRILLO, 2010, p. 17) se vê muito fortemente na trama de Kieren e Ricky. Exemplos disso acontecem já no momento da chegada de Kieren (com a necessidade de o jovem entrar escondido dentro de casa sob uma manta para despistar os vizinhos curiosos) e, logo mais, na primeira visita externa que a família recebe. Impelido pelo pai a se esconder dentro de um armário embaixo da escada enquanto a visita está na casa, Kieren começa a se sentir sufocado e rememora o momento em que acordou do mundo dos mortos ainda dentro do caixão. O duplo plano de significação coexiste na medida em que o armário relembra a situação simbólica dos jovens gays que não podem se assumir (e ainda "estão no armário") e, de igual modo, o confinamento do jovem Kieren dentro de seu esquife. Ambas as situações trazem a metaforização da homofobia no sentimento de clausura, de sufocamento dos movimentos, de angústia e ausência de liberdade dos sujeitos gays em sociedades homofóbicas (Figuras 2 e 3 ).

Ainda sobre a questão da homofobia familiar, o destino final do personagem Ricky representa muito bem algumas das reações mais vis dos pais em relação ao processo de coming out de seus filhos gays. Após passar a trama toda em constante dificuldade de aceitação, o jovem decide retirar a maquiagem que cobre o seu rosto (e que o torna mais próximo do humano, do aceitável, da norma) e, finalmente, apresenta-se ao pai do jeito que realmente é. O assassinato brutal do filho por parte do pai explicita simbolicamente como a violência contra a população gay não está ausente de espaços que, em tese, deveriam ser os de maior segurança e intimidade aos sujeitos. A metaforização da homofobia familiar se dá a ver pela abjeção paterna em relação à aceitação da condição do filho (ser zumbi/ser gay). A alteridade perde espaço para a violência física como saída e aniquilação da diferença (Figura 4 e 5). 


\section{I don't like confined space.}

\section{(OMINOUS WHISPERS)}

Figuras 2 e 3. Kieren e a metaforização da homofobia familiar.

Fonte: Frames de In the flesh, 2013 ( $1^{\text {a }}$ temp./10 ep.) - (CBBC3. 

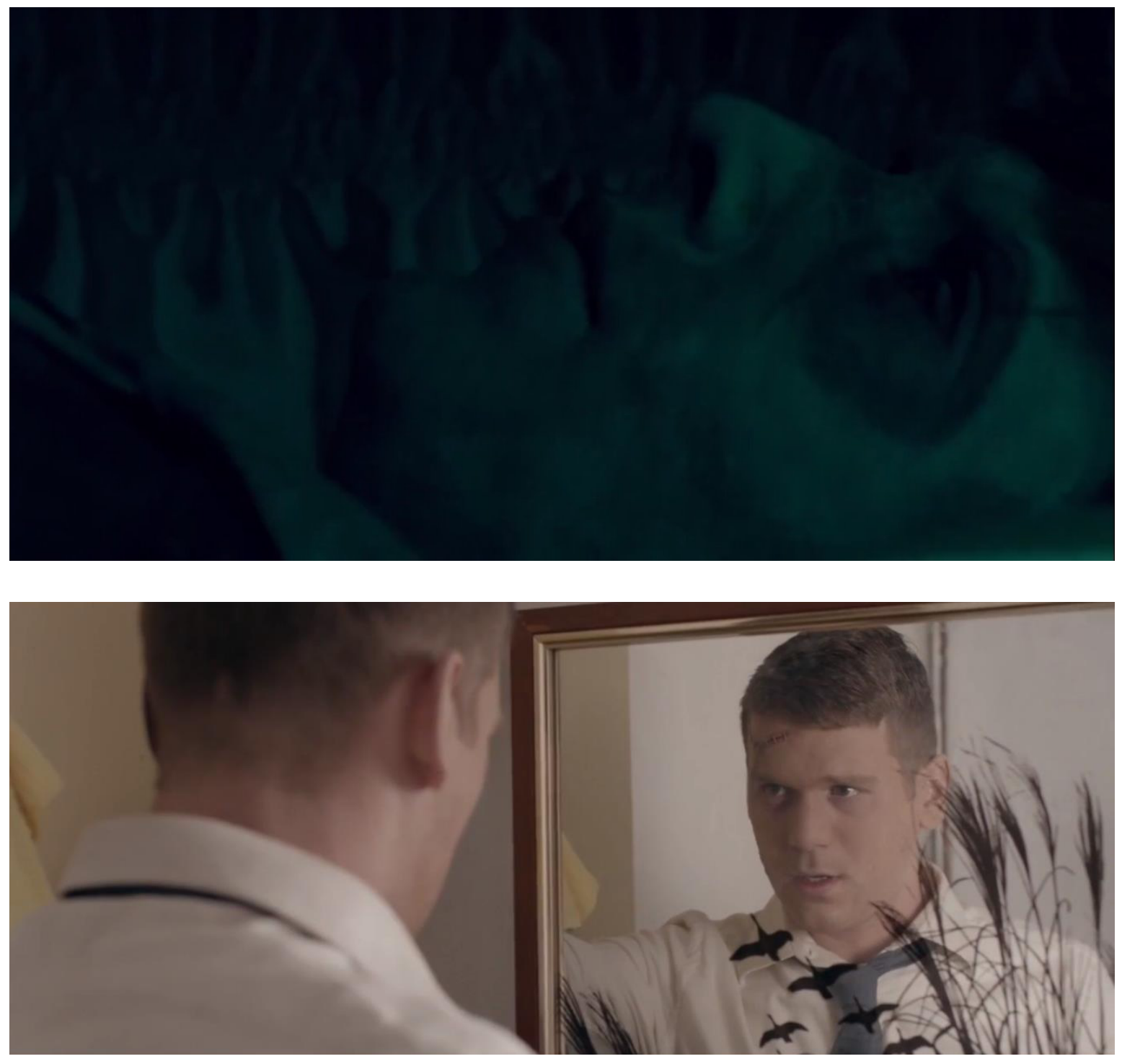

Figuras 4 e 5. Ricky e a metaforização da homofobia familiar.

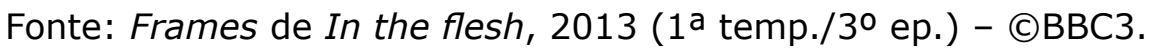

Em In the flesh, a homofobia de viés clínico (BORRILLO, 2010, p. 64) reforça a acepção patologizante de orientações sexuais dissidentes à heteronormatividade que, historicamente, esteve na base do entendimento da homossexualidade. Relembrando que foi com o psicólogo clínico George Weinberg que o termo homofobia primeiramente foi registrado em 1972, Junqueira (2007, p. 3-4) explica que: "Embora venha sendo paulatinamente ressignificado, o termo possui ainda fortes traços do discurso clínico e medicalizante que the deu origem. (JUNQUEIRA, 2007, p. 3-4)". Ainda no início da série, Kieren e outros zumbis 
estão em processo clínico de reabilitação (que, de maneira eufemista, tende a reprimir a identidade ou a condição de existência dessas pessoas para torná-las "normais"). Há aqui uma leitura metaforizada que retrata como a medicina, a psicologia e a psiquiatria ainda se veem rondadas por terapias apócrifas e outras situações pseudo-clínicas que intentam "transformar" ou "reverter" a orientação sexual de pessoas homossexuais em pessoas heterossexuais (Figuras 6 e 7).
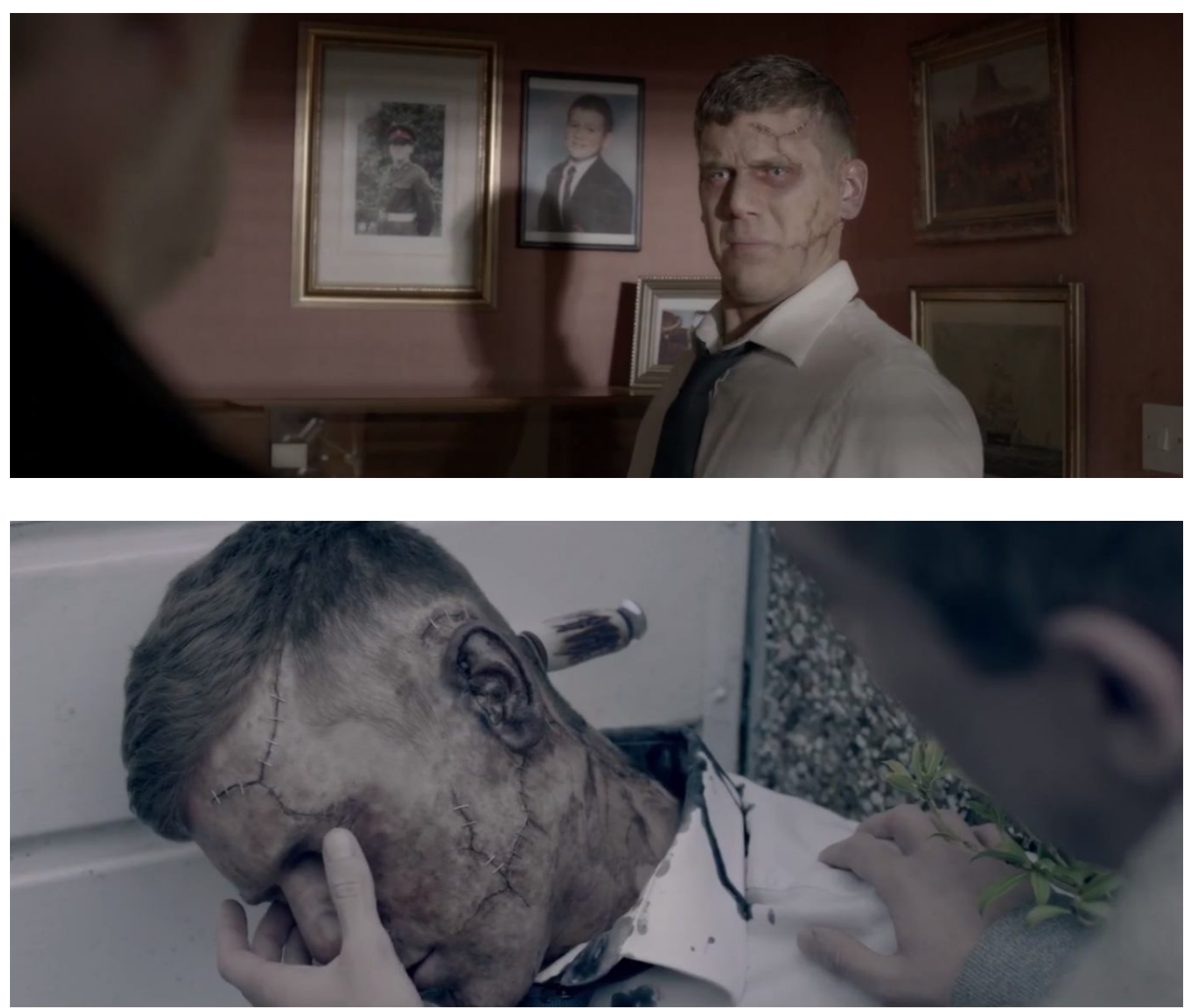

Figuras 6 e 7. Kieren e a metaforização da homofobia clínica. Fonte: Frames de In the flesh, 2013 (1 ${ }^{\text {a }}$ temp./10 ep.) - (CBBC3.

Outra discussão está no paralelo entre a medicamentalização da vida real com a vida ficcional: enquanto os zumbis precisam usar suas pílulas para manter a racionalidade e evitar o processo de zumbificação; na vida real muitas pessoas 
necessitam (e se viciam ao) usar pílulas e comprimidos para manter a sanidade mental, o sono e o funcionamento mais básico da mente e corpo humanos (já que sem esses medicamentos elas podem perder o controle total de suas vidas). Isto é: a narcotização mais uma vez passeia entre os efeitos de sentido nos dois planos de significação da isotopia discursiva. A concepção de cultura emocional, por sua vez, está ligada a uma atitude que envolve e faz referência à "crescente presença do discurso terapêutico e a sentimentalização em todas as esferas da vida social" que, por conseguinte, também permeia as tramas ficcionais nas TVs do mundo (GARCÍA MARTINEZ; 2016, p. 13).

Já a homofobia de viés religioso (BORRILLO, 2010, p. 59) ocorre na maneira como o padre da cidade estimula a população a não apenas encarar os mortosvivos como seres demoníacos e abjetos, como também deixa claro que a resposta divina ao problema é a eliminação desses sujeitos (Figuras 8 e 9). A Igreja vê a situação dos homossexuais como um impedimento apriorístico aos planos de Deus: "Enquanto comportamento sexual adequado, somente a heterossexualidade seria suscetível de permitir aos indivíduos a superação narcísica original (pecado) e o impulso para avançar ao encontro do outro" (BORRILLO, 2010, p. 60). A metaforização da homofobia em correlação ao preconceito da fé religiosa católica frente aos portadores da SMP revela-se, inclusive, pela hipocrisia: há, no templo, pessoas que se envolvem afetiva e sexualmente, às escondidas, com alguns dos mortos-vivos reabilitados (seja pelo matrimônio, seja pelo sexo casual).

Noutro ângulo analítico, a homofobia de viés "burocrático" ou institucional persecutório (BORRILLO, 2010, p. 78) está representada na série pela criação da Força Voluntária Humana (Human Volunteer Force - HVF) como meio de combate aos mortos-vivos. Fortemente armados e contando com o apoio declarado do Estado e da Igreja, a HVF mostra-se como uma milícia paramilitar que procura proteger os cidadãos de Roarton contra a ameaça dos desmortos. Se antes, durante o período da Ascensão, a HVF mostrou-se como necessária contra as hordas de zumbis famintos, nesse momento, passado o processo de reabilitação dos mortos- 
vivos e sua reintegração à vida cotidiana, a HVF promove uma verdadeira caça às pessoas portadoras de SMP (Figuras 10 e 11).

Além da ficção, a homofobia com caráter institucionalmente persecutório foi demonstrada na história global por meio das barbáries cometidas contra homossexuais durante o Holocausto, no período nazista, e durante o domínio stalinista na URSS (BORRILO, 2010. p. 82). Mesmo na contemporaneidade, a obra produz uma metaforização discursiva ao apontar caminhos que ligam a trama à perseguição homofóbica por parte de muitos países que criminalizam a prática homossexual ao redor do mundo.
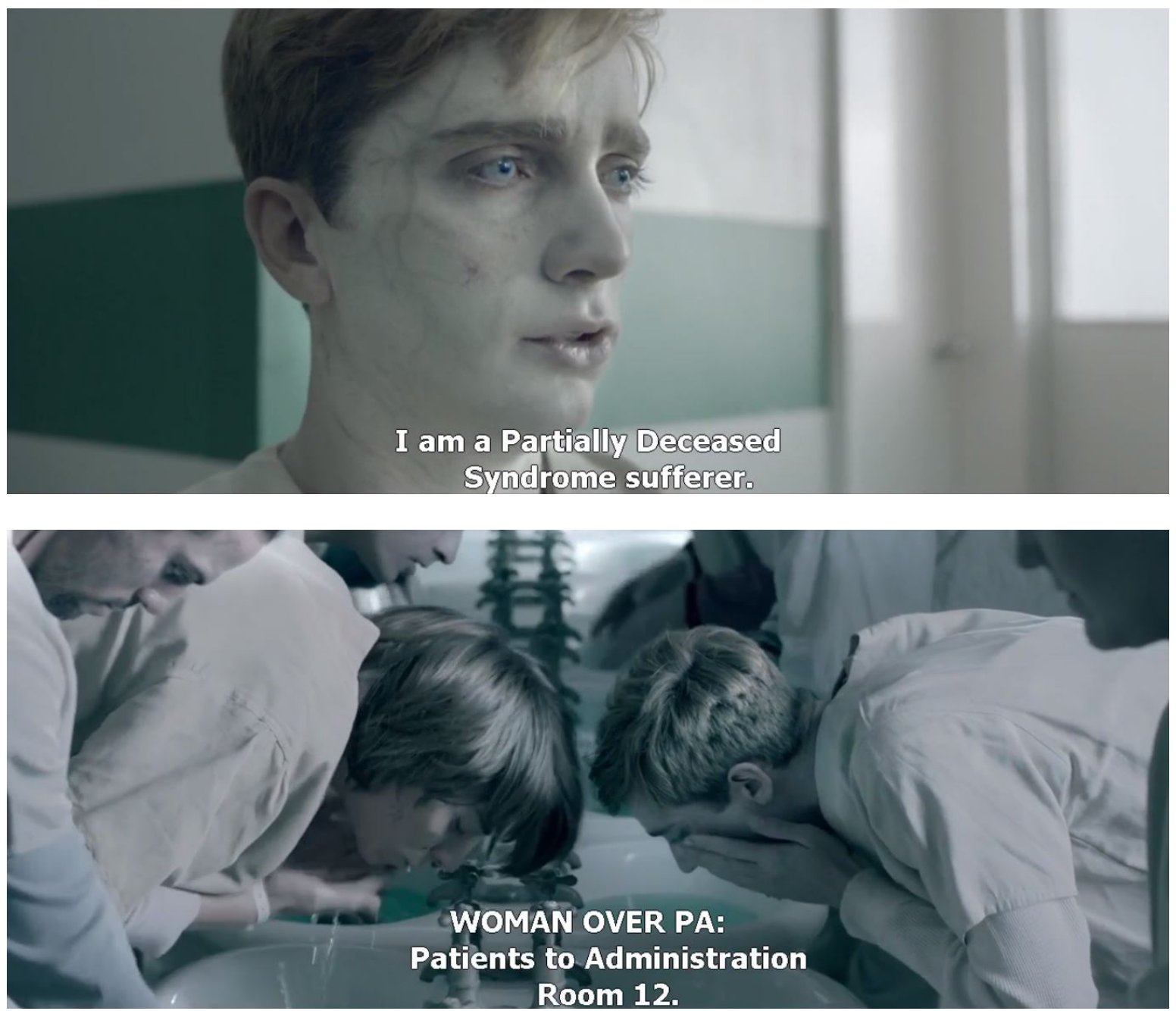

Figuras 8 e 9. A Igreja e a metaforização da homofobia religiosa.

Fonte: Frames de In the flesh, 2013 ( $1^{\text {a }}$ temp./10 ep.) - (CBBC3. 

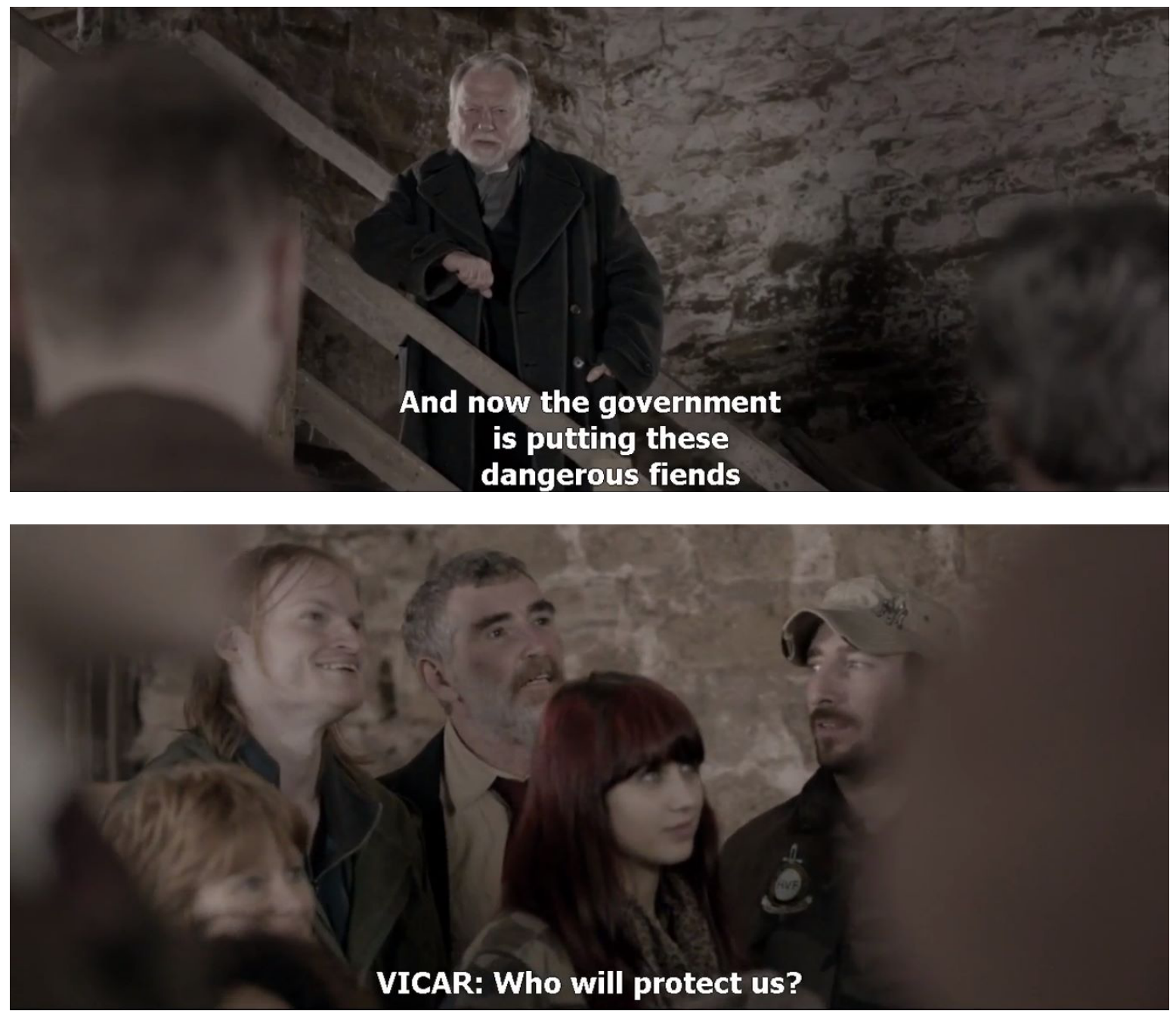

Figuras 10 e 11. A HVF e a metaforização da homofobia institucional persecutória.

Fonte: Frames de In the flesh, 2013 ( $1^{\text {a }}$ temp./10 ep.) - (CBBC3.

Finalmente, a homofobia de viés interiorizado (BORRILLO, 2010, p. 100) se dá a ver nos aspectos da sentimentalização desses personagens da série britânica, posto que é possível destacar a depressão e a melancolia como parte da vida (e do pós-vida) desses personagens. E, de igual importância, os processos de discriminação apresentam uma forte crítica às noções contemporâneas das castas que são preenchidas por minorias tidas tacitamente como "subcidadãs" (nesse contexto, a discriminação é dupla: pela situação de ser "zumbi" frente aos vivos e pela orientação sexual numa sociedade marcadamente heteronormativa). O uso da maquiagem como parte de disfarce dos zumbis que vivem com os vivos, lembra também o debate oportuno da crise com o próprio corpo e a autoestima 
em relação aos padrões de beleza (dificilmente alcançados) que são impostos aos jovens pela moda, pela comunicação midiática, por um estilo de vida hedonística e às vezes bem descolado da realidade de muitos. Em síntese, o "aparentar ser" ao invés do somente "ser".

Um exemplo muito específico de homofobia de viés interiorizado ocorre quando Ricky, já na condição de morto-vivo, insiste em beber várias bebidas alcóolicas no bar ao lado do pai e de outros homens homofóbicos. Mesmo sabendo que o ato de ingerir substâncias sólidas e líquidas é tóxico em sua nova condição, ainda assim, ele insiste. Quando confrontado por outra personagem que também é zumbi e sabe que a bebida Ihe fará mal, a resposta que ele Ihe dá é: "Eu não sou igual a você". Assim, a tentativa de manter a masculinidade perante os presentes na mesa e reafirmar em alto e bom som que ele é "normal" reforça os dois planos de significação que a cena mostra. O sofrimento do jovem que, imediatamente, acaba por vomitar no banheiro, traz ao centro da tela a questão da metaforização da homofobia interiorizada como o processo contínuo de negação e punição autoinfligida (Figuras 12 e 13). "O ódio da sociedade contra os homossexuais pode transformar-se em ódio a si mesmo [...]", relembra Borrillo (2010, p. 100-101). 

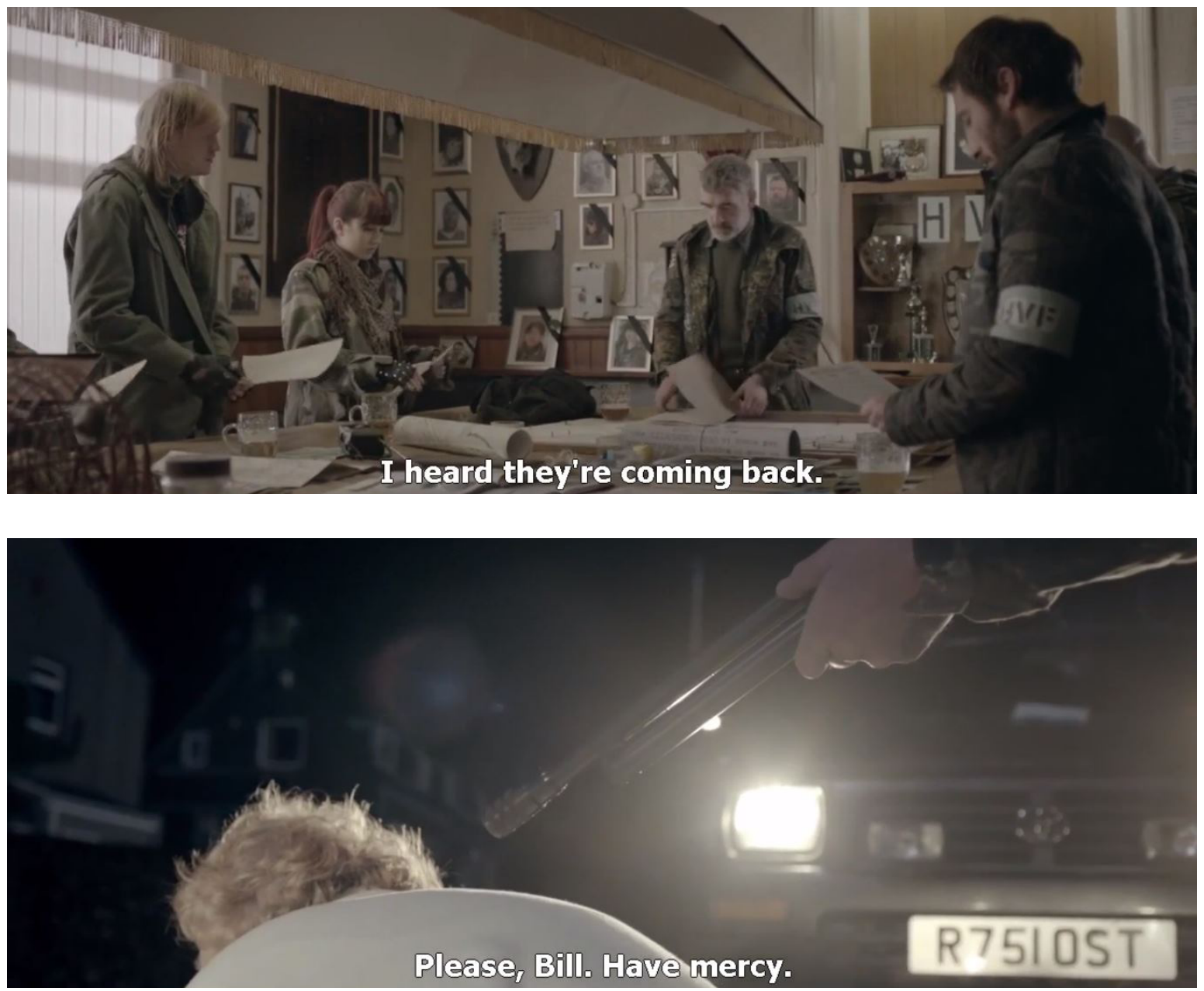

Figuras 12 e 13. Kieren e a metaforização da homofobia interiorizada.

Fonte: Frames de In the flesh, 2013 ( $1^{\mathrm{a}}$ temp. $/ 2^{\circ}$ ep.) - (c) BBC3

\section{Considerações finais}

O estudo das constituições e interrelações dos personagens zumbis da série In the flesh permite ao artigo propor um entendimento sobre como os processos de exclusão, preconceito, intolerância, discriminação e violência homofóbica (estrutural, institucional, física e psicológica) são constituídos por meio do tensinoamento entre o desejo e a abjeção que, por sua vez, orbitam ao redor da diferença enquanto elemento balizador comum. E, assim, as formas pelas quais o funcionamento da sociedade é norteado a partir de uma cis-heteronormatividade estrutural-estrurante tornam-se, limpidamente, apreensíveis na dupla articulação entre a ficcionalidade e a realidade. 
Dessa forma, o giro afetivo, a cultura emocional e a sentimentalização funcionam, juntas, como catalisadoras de uma discussão mais profunda que toca, diretamente, nas variadas materialidades discursivas nas quais a homofobia se dá a ver. No caso da análise em questão, foi possível destacar como a isotopia discursiva foi a chave de leitura dos processos de metaforização presentes em cenas que dão corpo à homofobia de viés familiar, de viés clínico, de viés religioso, de viés institucional persecutório e de viés interiorizado.

É dizer que, de antemão, o debate da abjeção não é de todo uma novidade no campo ficcional das narrativas de zumbis, todavia, do ponto de vista dos mortosvivos sentimentalizados percebe-se uma realocação mais ampla de produção de sentidos quando, na ausência de uma figura extremamente monstruosa, o ser abjeto ou tornar-se abjeto migra para outra esfera de significação: a ontológica. A pura existência do zumbi sentimentalizado, ainda que nem sempre caracterizada como um ser pútrido, em decomposição e bestial, já é a força mobilizadora suficiente para trazer a abjeção ao centro da reflexão. A existência de um zumbi gay, por sua vez, gera uma sobreposição ainda maior de abjeção que resulta, como a série demonstra, nas múltiplas tentativas e formas de anulação (simbólica e física) da diferença.

A tessitura narrativa da série In the flesh, como outras pesquisas já demonstram (COUTINHO, 2016; MONTES, 2017; AIOSSA, 2018), dá margem às discussões sobre gênero e sexualidade. Todavia, quando tais discussões são acessadas pela via da metaforização discursiva, o ganho interpretativo gerado por tal mobilização conceitual consegue exemplificar a riqueza da verbo-visualidade presente na trama. Logo, não apenas aspectos do texto verbalizado nos diálogos são levados em conta, como também a audiovisualidade importa. Isto é, não é possível discutir, por exemplo, a questão da dupla articulação de planos de significação na metaforização discursiva da homofobia interiorizada e da homofobia clínica sem se ater ao processo de caracterização física desses personagens. Ou seja, na leitura metaforizada posta em discussão neste artigo, há elementos materialmente da ordem verbo-visual que têm a potência analítica de visibilizar 
conexões entre a pretensa normalidade do homem (zumbi versus humano) à falsamente naturalizada heteronormatividade (homossexual versus heterossexual). Assim, a verbo-visualidade, nesse caso, aciona a isotopia discursiva na textualidade televisiva a partir do que Leite (2009, p. 126) chama de redundância de um efeito de sentido.

Não menos importante, por fim, foi trazer à luz a necessidade de um debate sobre os Estudos de Zumbis (Zombie Studies) colocados fora de um eixo acadêmico anglo-saxão ou pertencentes ao Norte Global. Os Zombie Studies, ainda, parecem estar à margem da legitimidade intelectual por justificativas que partem da "inferioridade" dispendida aos objetos de estudos tidos como "de qualidade questionável" e remontam, sobremaneira, à sisudez histórica da Academia em possibilitar aberturas à investigação de produtos e processos comunicacionais provenientes da indústria do entretenimento.

Por isso, faz-se urgente que o olhar da pesquisa volte-se a esses "objetos menores" para compreender como a sua discursividade é tecida e, com mais profundidade ainda, que outras pesquisas futuras possam desvelar novos processos de enunciação feitos por tais figuras sobrenaturais. Só assim, com um estudo meticuloso e livre de enviesamento aprioristicamente moral, é possível compreender a relevância de tais figuras zumbificadas e as reflexões nas quais se assentam os seus modelos de sociedade, contradições, alteridade e diferença.

\section{Referências}

AIOSSA, E. The Subversive Zombie: Social protest and gender in undead cinema and television. Jefferson: McFarland and Company, 2018.

ALLEN, R. H. The classical origins of modern homophobia. Jefferson: McFarland, 2006. 
AKOTIRENE, C. Interseccionalidade. São Paulo: Sueli Carneiro; Pólen, 2019.

BISHOP, K. W. How zombies conquered popular culture: The Multifarious Walking Dead in the 21st Century. Jefferson: McFarland \& Company, 2015.

BORRILLO, D. Homofobia: história e crítica de um preconceito. Belo Horizonte: Autêntica, 2010.

BUTLER, J. Problemas de gênero: feminismo e subversão da identidade. Rio de Janeiro, Civilização Brasileira, 2003.

CLOUGH, P. T. Introduction. In: CLOUGH, P. T.; CLOUGH, J. H. (orgs.). The Affective Turn: theorizing the social. Durham: Duke University Press, 2007.

COSTA, A. B.; NARDI, H. C. Homofobia e preconceito contra diversidade sexual: debate conceitual. Temas em Psicologia, v. 23, n. 3. Disponível em: http://dx.doi. org/10.9788/TP2015.3-15. Acesso em: 12 mar. 2020.

COUTINHO, R. S. Signos linguísticos e imagéticos da intolerância nos zumbis da série In the flesh. Tese (Doutorado). Universidade Federal de Goiás, 2016.

DENDLE, P. The zombie movie encyclopedia. Jefferson: McFarland \& Co., 2001.

GARCÍA MARTÍNEZ, A. N. ; GONZÁLEZ, A. M. Emotional culture and TV narratives. In: GARCÍA MARTÍNEZ, A. N. (org.). Emotions in contemporary TV series. New York: Palgrave Macmillan, 2016.

GARCÍA MARTÍNEZ, A. N. Prozac para zombis: La sentimentalización contemporánea del muerto viviente en la televisión. Brumal, v. IV, n. 1, primavera 2016. 
HANDERSON, J. Vodu no Haiti - Candomblé no Brasil: identidades culturais e sistemas religiosos como concepções de mundo Afro-Latino-Americano. Dissertação (Mestrado). Universidade Federal de Pelotas, 2010.

HURSTON, Z. N. Tell my horse: voodoo and life in Haiti and Jamaica. New York: Harper Collins, 1938.

JUNQUEIRA, R. D. Homofobia: limites e possibilidades de um conceito em disputa. Bagoas - estudos gays: gênero e sexualidades, v. 1, n. 1, jul.-dez. 2007. Disponível em: https://periodicos.ufrn.br/bagoas/issue/view/187. Acesso em: 23 abr. 2020.

KRISTEVA, J. Powers of horror: an essay of abjection. Nova York: Columbia University Press, 1985.

LEITE. R. L. Metaforização textual: a construção discursiva do sentido metafórico no texto. Tese (Doutorado). Universidade Federal do Ceará, 2007.

LEITE, R. L. Cognição e metaforização textual. In: MACEDO, A. C. P.; FELTES; Heloísa. P. M.; FARIAS, E. M. P. (orgs. ). Cognição e lingüística: explorando territórios, mapeamentos e percursos. Caxias do Sul/Porto Alegre: Educs/Edipucrs, 2008.

LEITE, R. L. Isotopia e metaforização textual. Gragoatá, v. 14, n. 26, 10 sem. 2009.

LOURO, G. L. Gênero, sexualidade e educação: uma perspectiva pós-estruturalista. Petrópolis: Vozes, 1997.

MCDANIEL, J. You can point a finger at a zombie. Sometimes they fall off: Contemporary Zombie Films, Embedded Ableism, and Disability as Metaphor. The Midwest Quarterly, v. 57, n. 4, 2016. 
McGLOTTEN, S.; JONES, S. Zombies and sexuality: essays on desire and the living dead. Jefferson: McFarland and Company, 2014.

MONTES, A. De los cuerpos travestis a los cuerpos zombis: la carne como figura de la historia. Buenos Aires: Argus-a, 2017.

REIS FILHO, L.; SUPPIA, A. Dos cânones sagrados às alegorias profanas: a laicização do Zumbi no cinema. Mneme, v. 12, n. 29, jul. 2011. Disponível em: https://periodicos.ufrn.br/mneme/article/view/1013. Acesso em: 31 maio 2020.

SILVA, A. L.; GARCÍA MARTINEZ, A. N. Um espectador-pesquisador: Alberto Nahum García Martínez e o estudo acadêmico sobre séries televisivas na Espanha (Entrevista). Ação Midiática, n. 13, jan.-jun. 2017. Disponível em: http://encurtador.com.br/ADI46. Acesso em: 23 abr. 2020.

SUPPIA, A. ; REIS FILHO, L. Marharhahar Z!namabarn: Breve panorama do cinema de zumbi na América Latina. Revista Rumores, v. 7, n. 13, jul. 2013. Disponível em: http://migre.me/w3NVy. Acesso em: 11 mar. 2020.

SZANTER, A.; RICHARDS, J. K. Romancing the zombie: essays on the undead as significant "other". Jefferson: McFarland and Company, 2017.

VERVAEKE, J.; MASTROPIETRO, C.; MISCEVIC, F. Zombies in Western Culture: a twenty-first century crisis. Cambridge: Open Books Publishers, 2017.

WRIGHT, K. Disgust and desire: the paradox of the monster. Amsterdam: Brill/ Rodopi, 2018.

Submetido em: 2 set. 20 | aprovado em: 14 out. 20 